\title{
A investigação da forma urbana em Minas Gerais, Brasil
}

\author{
An investigation of the urban form in Minas Gerais, Brazil
}

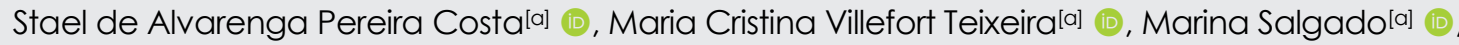
Maria Manoela Gimmler Netto[a] [a]

[a] Universidade Federal de Minas Gerais (UFMG), Escola de Arquitetura e Urbanismo, Belo Horizonte, MG, Brasil

Como citar: Costa, S. A. P., Teixeira, M. C. V., Salgado, M. \& Gimmler Netto, M. M. (2020). A investigação da forma urbana em Minas Gerais, Brasil. urbe. Revista Brasileira de Gestão Urbana, 12, e20200095. https://doi.org/10.1590/21753369.012.e20200095

\section{Resumo}

Este artigo versa sobre o estudo da forma urbana no Brasil e em Minas Gerais e constitui um desdobramento dos trabalhos publicados sobre essa temática. Ele contempla uma breve contextualização do tema no Brasil e, em seguida, a abordagem volta-se para o estado de Minas Gerais, apresentando relatos sobre a formação urbana e o desenvolvimento urbanístico. A ênfase do artigo concentra-se nos estudos morfológicos realizados na Escola de Arquitetura da Universidade Federal de Minas Gerais, cuja tradição iniciada na década de 1960 impulsionou pesquisas e constituiu desde essa época prática relevante dessa instituição. 0 método utilizado na elaboração deste artigo se baseia em fontes secundárias que empregam abordagens interdisciplinares. Aliados a essas questões têm-se os relatos fundamentados na compreensão dos fenômenos vivenciados pelas autoras de forma empírica ao longo de suas trajetórias profissionais e acadêmicas. São apresentados aprimoramentos com ênfase nos estudos que têm sido elaborados no campo da Arquitetura e Urbanismo, com a inclusão de aportes da paisagem. Assim, a intenção é demonstrar os produtos referentes à evolução do processo teórico e da aplicação dos conceitos morfológicos desenvolvidos no Laboratório da Paisagem da UFMG, a partir dos anos 2000

Palavras-chave: Morfologia urbana. Paisagem. Forma urbana. Laboratório da Paisagem. Inovação.

\section{Abstract}

This article aims the study of the urban form in Brazil and more specifically in the state of Minas Gerais, and is a development of work previously published on the subject field (reference, 2006, 2007, and 2014). A brief contextualization of studies performed in Brazil is followed by an examination of the state of Minas Gerais which draws on reports whose focus is the urban form and development. The article places emphasis on the morphological studies carried out at the School of Architecture at the Federal University of Minas Gerais (UFMG), whose tradition was inaugurated in the 1960s and has provided the inspiration and relevant practice for similar researches. Mainly the secondary sources, employing interdisciplinary

SAPC é arquiteta, doutora, professora, e-mail: staelalvarenga@gmail.com

MCVT é arquiteta, doutora, professora, e-mail: mcrisvt@gmail.com

MS é arquiteta e urbanista, doutora, professora, e-mail: ms.marinasalgado@gmail.com

MMGN é arquiteta e urbanista, doutoranda, e-mail: manoelagnetto@gmail.com 
approaches, providing the methodology used. In addition to this, the present study draws on the empirical experience of the authors accrued throughout their professional and academic trajectories. Finally, this research has hopefully enhanced understanding in the field with its emphasis on the importance of the landscape in the shaping of the urban form. Thus, the intention is to present and highlight the research items related to the evolution of the theoretical process and the application of morphological concepts developed in the Landscape Laboratory at UFMG since the start of the new millennium.

Keywords: Urban morphology. Landscape. Urban form. Landscape Laboratory. Inovation.

\section{Introdução}

A materialização dos registros de localidades no Brasil colonial inaugurou uma prática que se sistematizou como fonte para a busca do conhecimento sobre os primeiros assentamentos e sua forma urbana incipiente. Os primeiros registros referem-se, naturalmente, aos tempos de 1500 e às formas de morar indígenas. Na época do descobrimento do Brasil pelos europeus, os índios viviam em ocas que se constituíam de cabanas construídas com material ali existente e que mantinham com a paisagem a harmonia resultante da apropriação das construções com a natureza. Ao contato com os colonizadores, a influência sobre essa apropriação foi sendo adaptada e novas condições de assentamento se manifestaram com as respectivas adequações dos estrangeiros ao clima e às paisagens brasileiras.

No entanto, as primeiras cartas e os relatos referiam-se às áreas localizadas próximas ao litoral. Com a necessidade de expansão e apropriação do interior por parte dos portugueses, iniciam-se as expedições que traziam importantes revelações sobre a terra e a sua riqueza. Elas foram empreendidas para elaborar estudos sobre os territórios na América, no início do século XVI. Também os mapas desenhados por padres matemáticos, cartógrafos jesuítas por excelência, foram importantes registros para conhecimento do interior da nova colônia, sob contrato do rei.

Os engenheiros militares portugueses também possuíram função significativa para registrar os caminhos, assentamentos e estradas que permitiram acesso às mais diversas partes do território brasileiro, bem como demarcar as fronteiras com países vizinhos. A contribuição desses profissionais se deu pela construção racional de obras militares, civis e religiosas como fortes, quartéis, pontes, portos, hospitais, obras hidráulicas e de saneamento, aquedutos e hortos botânicos (Bueno, 2011).

No período das novas explorações dessa terra desconhecida nas paragens europeias, viajantes de diversas origens passaram a buscar novas fontes de cultura e vida nos países coloniais. Embora fosse vedada a entrada de estrangeiros no Brasil por defesa do seu patrimônio pela corte portuguesa, mesmo assim foram constantes as vindas de visitantes que percorreram parte do território e o descreveram com minúcias, dentre eles pintores, botânicos, zoólogos, geólogos, mineralogistas, filósofos e historiadores.

Os primeiros registros dos núcleos urbanos retratavam características físicas, históricas, culturais, sociais e econômicas, muitas vezes exemplificadas com ricos desenhos, que seriam apresentados ao país de origem como a visão de uma nova vida e riqueza exótica. Essas explorações possuíam abordagem predominantemente naturalista da paisagem, mesmo porque os centros urbanos da época se configuravam como pequenas aldeias, assentamentos formados espontaneamente com uma relação estreita entre o ambiente natural e o construído.

Importantes registros das paisagens no Brasil foram elaborados pelo pintor e botânico holandês Albert Eckhout, com as paisagens e a população indígena de Pernambuco, no Nordeste do Brasil, entre 1637 e 1644, e pelo pintor Jean Baptiste Debret, no Rio de Janeiro, de 1817 a 1831. Também Johann Moritz Rugendas, no período de 1822 a 1825, percorreu as províncias costeiras do Rio de Janeiro, Minas Gerais, Pernambuco, Bahia, São Paulo, Mato Grosso e Espírito Santo apresentando em suas pinturas a gênese do povo brasileiro. Os naturalistas alemães Johann Baptist Von Spix e Carl Friedrich Von Martius 
estudaram a fauna brasileira e de Minas ao percorrer o rio São Francisco, entre 1817 e 1820 (Suplemento Literário de Minas Gerais, 1970).

Minas Gerais se manteve fechada à curiosidade dos viajantes estrangeiros durante quase todo o período colonial. A vigilância da Coroa explica a ausência de estudos ao longo do período. 0 mineralogista John Mawe abre o ciclo de visitantes, no início do século XIX, ao conseguir a primeira carta régia para penetrar na zona de mineração. Nesta época, a Capitania já estava decadente, mas ele registrou os principais distritos produtores de ouro e diamantes. 0 trabalho do geólogo e mineralogista Wilhelm Ludwig von Eschwege, que esteve no país entre 1810 a 1821, trouxe contribuições sobre mineração e potencialidades para a implantação de futuras siderúrgicas no Brasil.

Vila Rica era o lugar mais procurado pelo fato de ser uma urbanização estruturada e onde se concentrava a administração da província. As viagens do comerciante John Luccock, do médico e capelão Robert Walsh, dos médicos e botânicos George Gardner, Johann Baptist Emanuel Pohl e do naturalista Francis Castelnau trouxeram informações importantes sobre a paisagem e a população das vilas mineiras, incluindo Vila Rica, Diamantina, Paracatu, Congonhas do Campo, Sabará, Mariana, São João Del Rei, São José Del Rei, atual Tiradentes, dentre outras (Suplemento Literário de Minas Gerais, 1970).

Os trabalhos do botânico Auguste Saint-Hilaire em toda a província de Minas, de 1816 a 1822, e do geógrafo Richard Francis Burton, que se estendeu pelo rio São Francisco em 1867, sobressaíram nas descrições da fauna e da flora, das cidades e dos costumes da população de Minas da época. Os dois autores percorreram o Brasil e quase toda Minas Gerais, retratando especialmente detalhes preciosos do território diamantinense (Suplemento Literário de Minas Gerais, 1970).

Embora existisse um número significativo de relatos sobre as vilas mineiras, ainda não havia evidências de alguma investigação relacionada à forma urbana. Geralmente, os relatos se restringiam a comentários sobre as vilas e os arraiais com suas casas esparsas e as poucas ruas esburacadas, os costumes, os fatos sociais e econômicos, com ênfase nas características de exploração do ouro e do diamante. Mas é a partir desses relatos e dos desenhos de algumas cidades mineiras que é possível perceber os principais traços da forma urbana no período.

No início do século XX, vários estudos sobre as cidades surgiram no Brasil, mas eles se assemelhavam,

[...] pois discutiam, obrigatoriamente, seis conteúdos analíticos: o sítio, a posição, a evolução histórica, a fisionomia e estrutura, as funções urbanas e o raio de ação da cidade. Ricos no que toca à descrição e à análise das formas materiais, esses estudos pecavam, entretanto, pela pouca vinculação que estabeleciam entre os padrões urbanos que detectavam e os processos sociais que lhes haviam dado origem e/ou desenvolvimento. (Abreu, 2002, p. 46).

Apesar da boa análise com os condicionantes naturais e os aspectos cartográficos, pouco se tratou das ações sociais no espaço e muito menos da investigação da Morfologia Urbana, que relaciona os processos sociais à evolução da forma urbana ao longo do tempo.

Essa retropectiva ilustrou como estudos morfológicos foram pouco significativos para os viajantes e estudiosos durante os séculos XVIII e XIX, cujo intuito era apenas a descrição das suas características gerais. No entanto, no final do século XIX, observam-se estudos muito detalhados sobre sítios urbanos e melhor conformação para a implantação da nova capital do estado, aspecto a ser discutido na primeira parte deste artigo, juntamente com estudos de cidades projetadas.

É a partir do século XX que pesquisas são sistematizadas com base no trabalho de Sérgio Buarque de Holanda (2014) e Gilberto Freyre $(1933,1936)$, que iniciam as análises sobre as formas e as suas relações políticas e sociais. Dentre os estudos da forma urbana no século XX, vale ressaltar Sérgio Buarque de Holanda (2014, p. 130), que compara Salvador, São Vicente e Santos às cidades espanholas, salientando que as casas das cidades brasileiras estavam dispostas segundo "o capricho dos seus moradores", sem organização, com as casas em desalinho. 0 traçado geométrico, embora utilizado no país, jamais pôde alcançar a importância que possuía naquelas vilas, pois obedecia antes às condições topográficas. Essa estruturação se manteve também nos arraiais do interior, visto que as imposições da corte estavam 
distantes para serem contempladas e, além disso, os caminhos da exploração em Minas não seguiam direcionamento tão rigoroso.

Portanto, a primeira parte do artigo apresenta, por meio de exemplos em localidades, como ocorreu o processo de urbanização em Minas Gerais. As incipientes formas urbanas conhecidas como "passagens", destinadas ao pouso dos viajantes em rotas, com a especialização de atividades econômicas ao passar do tempo, se transformavam em arraiais. Os arraiais se desenvolveram como núcleos urbanos em diferentes regiões do estado, sempre conectados por rotas, formando uma rede urbana mineira, durante o período colonial. Os mais importantes do ponto de vista estratégico para a Coroa portuguesa ou que exerciam maior atração populacional eram elevados à categoria de vilas. Por fim, a consolidação do espaço urbano mineiro em cidades concretiza-se a partir da independência do país.

A segunda parte do artigo traz reflexões a respeito da influencia dos estudos sobre a formação colonial mineira no desenvolvimento de pesquisas na Escola de Arquitetura da UFMG, na década de 1960, e que constitui uma linha tradicional de investigação, cujo objetivo é a preservação cultural. Em continuidade a essa prática organizam-se grupos de pesquisa em laboratórios, tendo como destaque o Laboratório da Paisagem, que a partir dos anos 2000 integra a bordagem da Morfologia Urbana aos estudos de paisagem. As considerações finais destacam o avanço do estudo da Morfologia Urbana no país e em Minas Gerais, tanto em termos conceituais como em aplicações práticas, resultando em publicações relevantes sobre o tema.

\section{Os primórdios da forma urbana nas Minas Gerais}

0 processo de interiorização em busca de metais preciosos encorajou as inúmeras expedições que, desde a segunda metade do século XVI, investiram no desbravamento e descoberta da região que seria conhecida como Minas do Ouro. A primeira delas, enviada para o descobrimento das esmeraldas, saiu da Bahia e penetrou nos sertões mineiros em fins de 1553, princípio de 1554, a mando de Duarte da Costa, tendo Francisco Bruza Spinosa à sua frente (Barreto, 1996). A Bandeira de mais vulto, contudo, e que efetivamente descobriu as Minas Gerais, foi a de Fernão Dias, que partiu de São Paulo em 1674, passando pelo Vale do Paraíba e Serra da Mantiqueira, e foi estabelecendo pousos ao longo do caminho, tais como: Serro Frio, Roça Grande, Sumidouro, Esmeraldas, entre outros (Lima, 1962). Esses povoados foram criados a partir da instalação das bandeiras para descanso das tropas em forma de pousos junto aos caminhos e deram origem a cidades que chegaram até nossos dias. A partir da aventura de Fernão Dias, os caminhos estavam abertos, possibilitando maiores investidas nos desconhecidos campos das Gerais.

Vale destacar um desses pousos de descanso do bandeirante Fernão Dias e sua tropa, que deu origem ao arraial do Sumidouro, ocupado em 1675. A partir de um mapa de 1732 (Delson, 1979), o primeiro registro da forma urbana em Minas possibilita interpretar o que seria a forma urbana no período do Brasil Colônia (Figura 1). Uma característica marcante é a transitoriedade da ocupação, assim como a espontaneidade e a falta de ordenamento das edificações, com exceção da igreja e seu largo, que possuem cuidado com a geometria do espaço. A leitura desta figura nos indica a implantação das edificações em níveis distintos com a criação de alguns taludes, em função do terreno acidentado e sem alinhamento frontal.

Além disso, é nítida a importância dada aos caminhos de acesso que configuram as principais rotas de entrada e saída do assentamento, respeitando, em geral, as cotas de nível do terreno. Esses caminhos, não somente nesse assentamento, mas em via de regra geral nas ocupações em Minas, acabavam por se tornar a via principal dos arraiais e, posteriormente, das futuras cidades. 0 contato com a água, representado pela lagoa do Sumidouro, também é crucial para o início da implantação do assentamento. Esse aspecto foi regulamentado mais tarde pela legislação que orientava a ocupação das comunidades em "[...] sítios saudáveis, próximos de rios e de fontes de água boa, com terreno propício e a pouca distância das minas de ouro [...]" (Boxer, 1969, p. 147). 


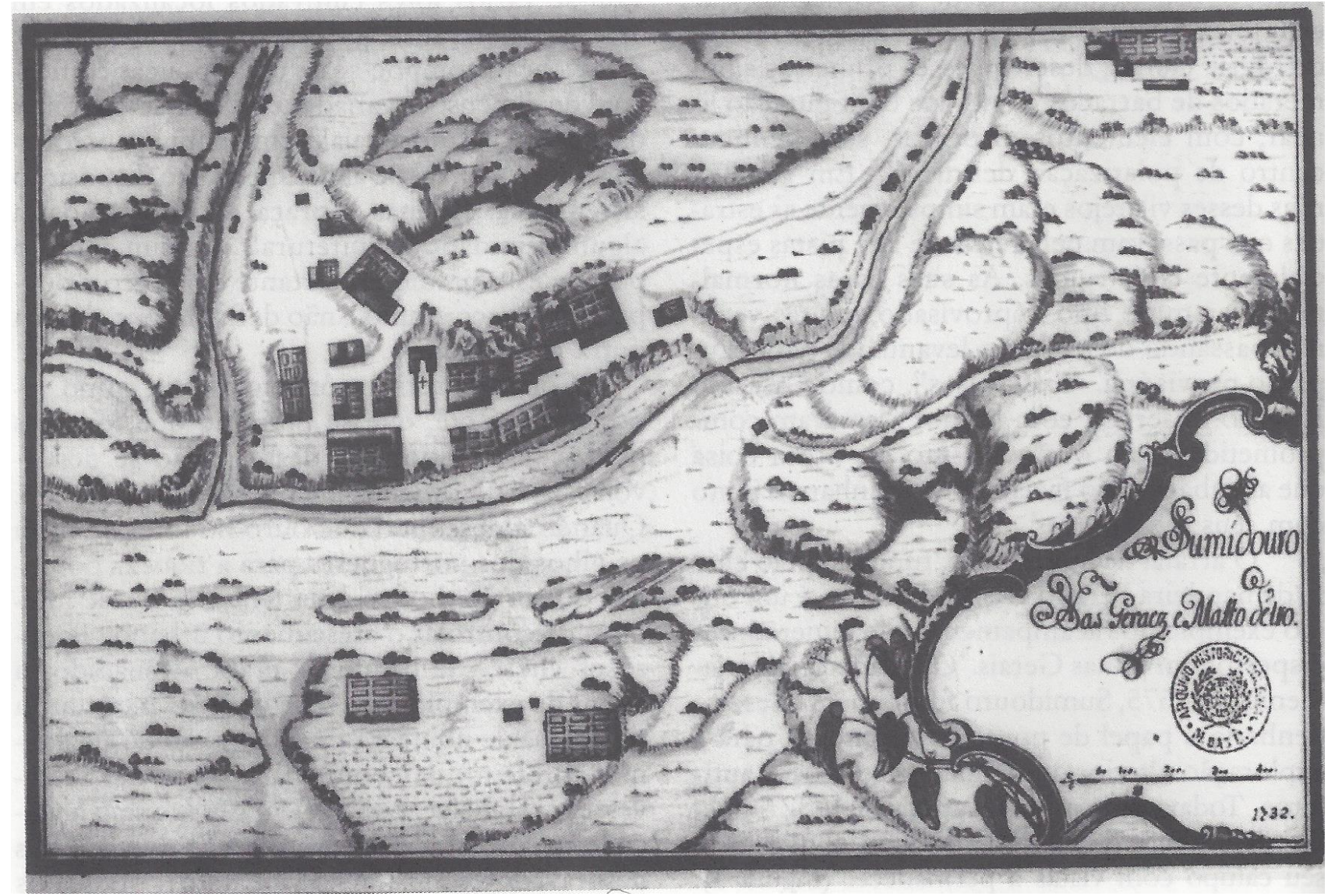

Figura 1 - Planta básica de Sumidouro, em Minas Gerais, 1732. Fonte: Delson (1979, p. 28).

Um arraial que merece destaque em Minas Gerais em função da elaboração de um planejamento para sua posterior implantação, modelo que não era comum na região, foi a atual cidade de Mariana. Denominada inicialmente Arraial de Nossa Senhora do Carmo, foi uma das primeiras vilas surgidas na região, juntamente com Ouro Preto e Sabará. Assim como grande parte dos assentamentos das Minas, este arraial foi implantado por uma lógica espacial de adaptação ao relevo, tanto no que diz respeito à escolha do sítio quanto ao traçado das vias, quarteirões e lotes.

O núcleo primitivo e de traçado espontâneo encontrava-se implantado às margens do Rio do Carmo, porém em 1742 ele transbordou inundando e destruindo grande parte da área construída do arraial. A Coroa, então, providenciou a elaboração do plano urbano de uma cidade inteiramente nova situada em um terreno mais elevado que o anterior. "Surgia a oportunidade não só para corrigir os equívocos urbanísticos das vilas mineiras como para - e isto era o mais importante - construir uma bela sede para a recém-criada diocese de Minas Gerais" (Delson, 1979, p. 37).

José Fernando Pinto Alpoim, engenheiro militar a quem foi atribuído o projeto da cidade de Mariana, demonstra claramente a necessidade de se estabelecer o ordenamento urbanístico através da regularidade da forma urbana. As vias, quarteirões e lotes apresentam-se de forma ortogonal, sendo que as edificações deveriam estar alinhadas na testada do lote e possuir características semelhantes, dando ideia de conjunto coeso na paisagem. Assim, o projeto da Coroa de demonstrar a ordem e a precisão de suas intervenções teve na figura dos engenheiros militares seus principais expoentes para garantir o plano carregado de significado de controle cada vez maior da colônia pela Coroa.

A Figura 2 apresenta a planta da cidade de Mariana, concebida por Alpoim. Nela pode-se observar o rigor formal e a implantação de uma malha ortogonal que se estrutura a partir de uma praça central onde se encontra a Igreja Matriz e a Casa de Câmara e Cadeia. 


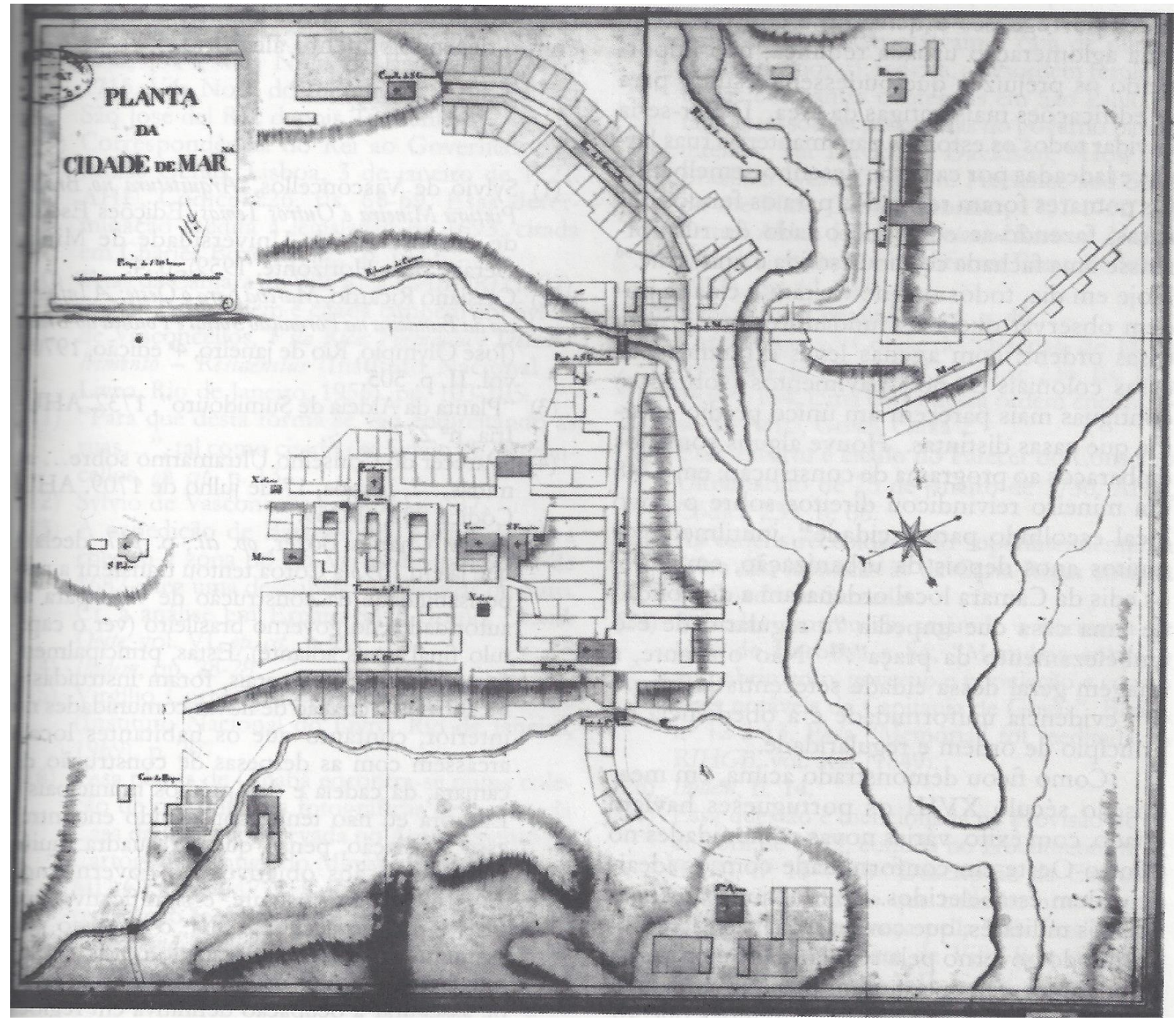

Figura 2 - Planta da reconstrução de Mariana, Minas Gerais (1746-1747). Fonte: Delson (1979, p. 37).

No final do século XVIII, o ouro de superfície já havia se esgotado e a quantidade imensa desse minério existente no subsolo exigia tecnologia específica utilizada por companhias estrangeiras. Nos meados do século XIX, empreendimentos minerários estrangeiros trazem inserções de modelos de companhias industriais que são incorporados às malhas tradicionais coloniais (Teixeira et al., 2019a). Padrões semelhantes aos implantados nas cidades inglesas e americanas inspirados em esquemas utilizados por Owen e Unwin são replicados em ocupações mineiras com reservas auríferas que se localizam no vale do rio das Velhas e na região do Quadrilátero Ferrífero. A descrição detalhada dos núcleos, a hierarquização das habitações e os tipos específicos foram relatados por Burton, que em 1867 visitou a região, como também Marianne North (Gazzola, 2001).

Estes modelos reforçam e influenciam posições opostas às tradicionais, consideradas retrógradas e alinhadas aos ideais dos antigos colonizadores. A partir desta experiencia, seguem-se outras nas quais se reproduzem modelos modernistas para a implantação de novas cidades, como, por exemplo, Ipatinga, Ouro Branco e várias pequenas vilas para abrigos de operários de companhias estatais (Guerra, 2008).

É também nesta ocasião, final do século XIX, que a insatisfação com o regime administrativo em vigor leva à busca por novas ideologias e modos de governar que culminam na implantação da República conduzida pela ideologia positivista. E, para reafirmar o novo modelo republicano, elege-se um arquétipo que simbolizasse a construção de uma nova capital para o estado de Minas Gerais, Belo Horizonte (Reis, 1968).

A cidade moderna deveria ser racional, setorizada e atender a determinadas funções previamente definidas. Nesse sentido, grande parte dos projetos de modernização de Ouro Preto, até então a capital 
da província, não foi executada e com isso a cidade perde seu poder econômico e político. A cidade de Belo Horizonte, escolhida para nova sede, se transformaria em apenas quatro anos na capital do estado, instalada em 12 de dezembro de 1897 (Pinto, 1907).

Estudos elaborados pela Comissão Construtora sobre o melhor local para a implantação da capital, bem como o projeto e suas especificidades, constituem os maiores registros do período, que podem ser observados nos relatos detalhados de Abílio Barreto (1996). A cidade foi concebida a partir de projeto urbanístico do engenheiro Aarão Reis, que previa a localização das zonas urbana e suburbana. Na área urbana estavam previstos os principais espaços livres públicos, as praças, o parque e os jardins. A ideologia positivista se materializa sob a forma de modelos que privilegiam a métrica e a tecnologia que foram a base para a proposta da malha ortogonal com quarteirões quadrados, separados por vias largas e avenidas diagonais implantadas sobre um planalto em declive (Barbosa, 1967), como pode ser observado na Figura 3.

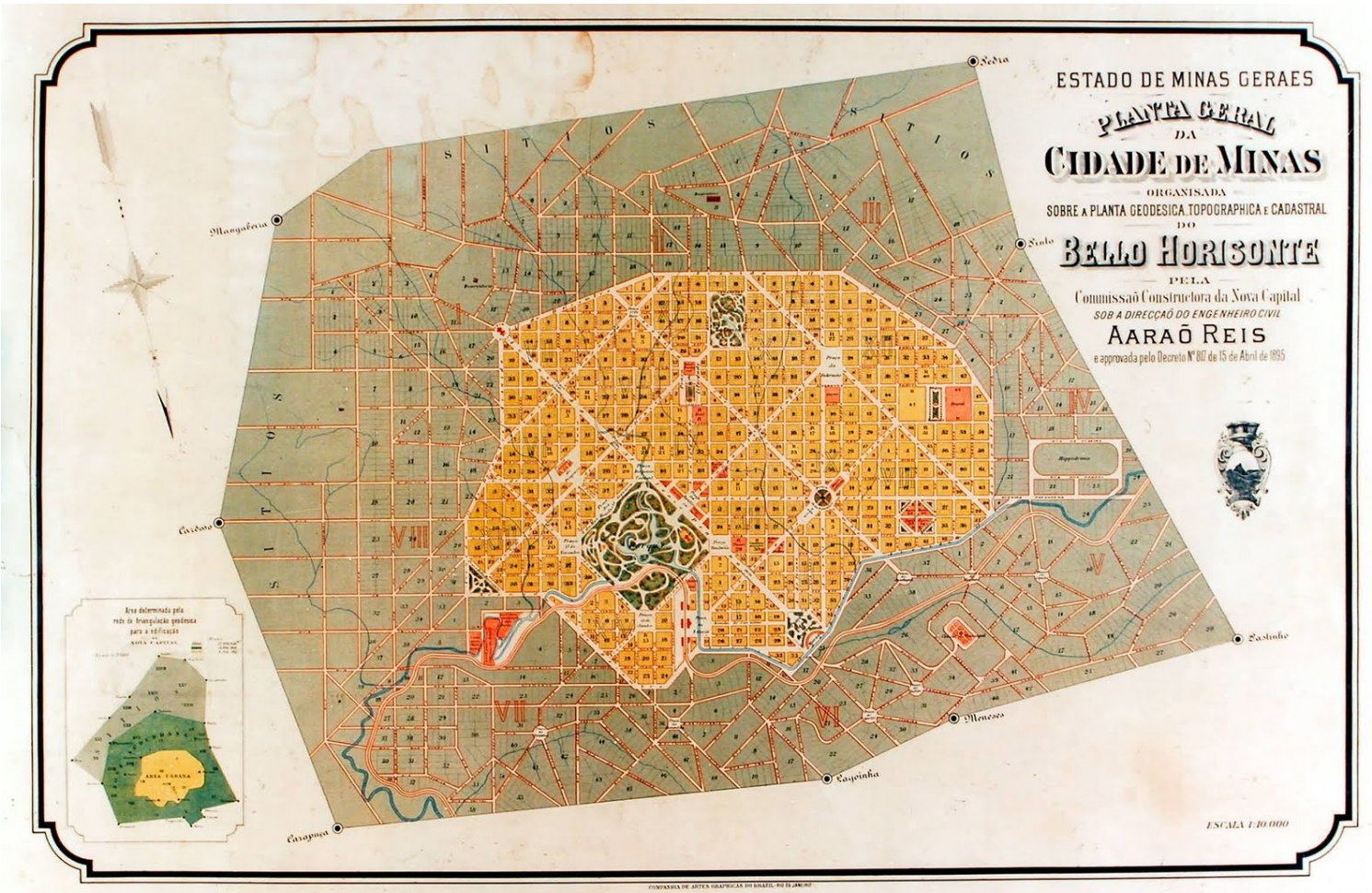

Figura 3 - Planta geral da cidade de Belo Horizonte, 1887. Fonte: Gomes (1895).

Duas décadas após a inauguração da nova capital de Minas Gerais, marco do Modernismo no estado, inicia-se uma busca pelos integrantes da Semana de Arte de 1922, das raízes da cultura brasileira, reconhecendo o modelo tradicional das cidades coloniais como um símbolo nacional a ser preservado e referenciado pela ideologia moderna. Sob esta influência, em 12 de julho de 1933, Ouro Preto é decretada Monumento Nacional e a criação do SPHAN, em 1937, foi fundamental para sustentar este projeto modernista do Estado Novo, no intuito de reconhecer um passado para a nação (Pereira Costa et al., 2011).

Desse fato surgem políticas específicas que vão privilegiar a valorização e a preservação desse patrimônio cultural e inauguram novo campo de estudos morfológicos que privilegiam as formas urbanas tradicionais mineiras.

\section{A Escola de Arquitetura da UFMG e suas correntes didáticas ideológicas}

A criação da Escola de Arquitetura (EA) da UFMG, na década de 1930, ocorre sob a influência modernista, que reflete no currículo maior ênfase na obra arquitetônica que em estudos urbanísticos. Por 
outro lado, os ideais que preconizavam o respeito às tradições pelo movimento modernista e consequente valorização das formas urbanas e tipologias de influência colonial portuguesa encontram espaço nos estudos que estavam sendo desenvolvidos por Lúcio Costa em nível nacional. As investigações de Costa (1995) identificavam em Diamantina e nas demais cidades coloniais mineiras tipologias edilícias que revelam semelhanças com o processo tipológico preconizado por Saverio Muratori, fundador da Escola Italiana de Morfologia Urbana.

O professor da EAUFMG Sylvio de Vasconcellos integrava a equipe do Instituto do Patrimônio Histórico e Artístico Nacional e desenvolve pesquisas morfológicas inovadoras sobre a evolução urbana e sobre as tipologias edilícias dos núcleos coloniais mineiros. É possível identificar certa semelhança de abordagem entre os estudos urbanos realizados por Vasconcellos e os fundamentos teóricos da Escola Inglesa de Morfologia Urbana, consequente da análise sistemática de determinados períodos de tempo e a identificação de elementos estruturadores do processo de formação e evolução urbana. Mais uma vez, os estudos sobre as tipologias edilícias revelam semelhanças com os processos de transformação tipológica elaborados por Saverio Muratori.

As pesquisas de Sylvio de Vasconcellos $(1968,1977)$ sobre as cidades coloniais foram pioneiras no desenvolvimento de estudos morfológicos em Minas Gerais, nos anos 1960. Os inúmeros materiais produzidos resultaram em um grande acervo, construído ao longo do tempo, que está preservado e disponibilizado no Laboratório de Fotodocumentação da EAUFMG. Esses documentos permitem a vinculação dos registros de várias cidades do estado como fonte para investigar a evolução e a estrutura morfológica, bem como aspectos relacionados aos tipos edilícios coloniais.

Esses estudos inéditos inauguram uma linha de pesquisa e a formação de um grupo que consolida uma tradição e cujos produtos levantados constituem um importante acervo. Esse grupo de pesquisadores desenvolveu abordagens voltadas à preservação cultural e obteve reconhecimento nacional e internacional. Pelos acontecimentos políticos e perseguições relativas ao período da ditadura militar que se implantou no país na década de 1960 esse processo é interrompido. Isso culmina com a expulsão do professor Sylvio e seu exílio em outro país. Após a interrupção de vários anos nas pesquisas, ocorre uma retomada conduzida nos anos 1990, com o restabelecimento do Laboratório de Fotodocumentação da EAUFMG pelo professor Leonardo Barci Castriota.

Os estudos realizados por Sylvio de Vasconcellos repercutiram na prática como embasamento para a elaboração de políticas públicas após a redemocratização do país, na década de 1980, sob a coordenação de órgãos estatais da Secretaria de Planejamento e suas autarquias, como o Plambel (Belo Horizonte, 1984a, 1984b, 1984c) e a Fundação João Pinheiro. Dessa fase são elencados os estudos sobre ocupações espontâneas visando à regularização fundiária e definição de vias para a implantação de infraestrutura urbana. Os conceitos morfológicos utilizados consistiam basicamente no emprego da figura-fundo para definição de espaços livres e privados e nos estudos sobre a evolução urbana. Esses métodos foram também empregados na escala dos centros históricos, realizados pela Fundação João Pinheiro (FJP, 1980). As discussões desses conceitos e das teorias morfológicas que motivam a sua aplicabilidade nas ocupações espontâneas, na regularização de favelas e na organização da forma e das tipologias edilícias constituem exemplos marcantes no desenvolvimento da cidade e fundamentam a política habitacional da época.

Dessa experiência adquirida sucedem-se outras atividades que se ampliam para pesquisas didáticas, com a transmissão destes conhecimentos nos cursos de Percepção Ambiental, realizados no Instituto de Geociências da UFMG, e que acrescentaram uma nova tendência de estudar o espaço urbano. As funções sociais associadas ao espaço urbano preconizavam a interdisciplinaridade e ampliavam o olhar para a cidade. Embora estudos morfológicos sobre áreas de ocupação espontânea fossem de importância fundamental para a regularização fundiária, os assuntos cotidianos de políticas públicas municipais se sobressaíam sobre os estudos formais desejáveis, que não foram aplicados. Mesmo assim, representam um incipiente vislumbre das possibilidades que poderiam ser desenvolvidas como uma pesquisa formal.

As primeiras pesquisas morfológicas formais sob a influência de Sylvio de Vasconcellos tinham como objeto de investigação cidades sul-metropolitanas de Belo Horizonte, que incorporaram modelos de 
companhias industriais nas formas de origem colonial portuguesa. Para esses estudos, as abordagens das escolas inglesa e italiana complementaram o entendimento da forma urbana da cidade e os respectivos tipos edilícios dali provenientes.

No início dos anos 2000, atividades de extensão passaram a ter importância para subsidiar pesquisas que reuniam professores e estudantes de Arquitetura em projetos para cidades mineiras que buscavam aportes metodológicos para aplicação em áreas de ocupação subnormal, no Programa de Arquitetura Pública, como em Barbacena, Minas Gerais (Pereira Costa \& Maciel, 2008; Pereira Costa et al., 2010). Outras atividades compreenderam a realização de seis planos diretores para cidades mineiras e permitiram novamente, com maior rigor, demonstrar a versatilidade dos estudos morfológicos na aplicação de políticas para estabelecimento de zoneamentos e perímetros de expansão por meio de estudos da evolução urbana. Outra contribuição presente nesses planos se deu pela inserção dos estudos tipológicos para o estabelecimento de modelos de parcelamento e padrões de uso e ocupação do solo, aliados aos estudos de conforto ambiental e direção dos ventos. Processo semelhante ocorreu na elaboração dos Planos de Habitação de Interesse Social (PLHIS), que seguiram o mesmo processo metodológico e aplicação nas pesquisas morfológicas (Teixeira et al., 2010, 2011a, 2011b). Esses estudos interdisciplinares trouxeram inovações para os trabalhos de morfologia pela ampliação da escala e incorporação da variável paisagem, que incluíram em seu arcabouço a paisagem urbana, a ecologia da paisagem e a estruturação do território em larga escala, desenvolvidos em cursos de extensão, graduação e pós-graduação.

Como parte do trabalho integrado e indissociável de pesquisa, extensão e ensino, os resultados dessas atividades eram discutidos e aplicados na prática didática da Morfologia Urbana no curso de especialização em Revitalização Urbana. Cada vez mais era premente a necessidade de experimentar novas aplicações na disseminação dos conceitos contidos nos aportes das escolas tradicionais de Morfologia Urbana e sua interlocução com a paisagem. Na graduação, a disciplina Projeto Integrado de Arquitetura e Urbanismo (PIAU) contemplava um dos eixos de leitura da paisagem visando à compreensão da formação e transformação da área estudada. Porém, à medida que as atividades didáticas se desenvolviam, adequações e ajustes foram se fazendo necessários e exigiram ações visando melhor absorção dos conceitos que possibilitassem futuras aplicações tanto na prática projetual quanto na acadêmica. Nessa prática, observou-se a necessidade de oferta dos diversos conceitos morfológicos que permitiriam estudos comparativos e à integração aos estudos geográficos, formais da paisagem urbana, bem como aos arquitetônicos e sua evolução tipológica.

Ao mesmo tempo, constatou-se que os textos que continham os aportes morfológicos eram em língua estrangeira, inglesa ou italiana, e por isso nem sempre eram compreendidos pelos alunos. E, mesmo que fossem discutidos e aplicados na realidade brasileira, havia necessidade de decodificação do método e suas respectivas aplicações, o que exigia estudos detalhados. Parte deles foi resolvida com a tradução de textos clássicos dos fundadores das escolas tradicionais (Conzen, 2009) e fundamentaram seminários para discussão dos conceitos básicos dessas escolas no Laboratório da Paisagem, criado em 2008. Ainda assim, lacunas conceituais permaneciam recorrentes nas aulas e estudos subsequentes.

As teorias morfológicas instigaram estudantes da linha de pesquisa Paisagem e Ambiente do Programa de Pós-Graduação em Ambiente Construído e Patrimônio Sustentável (PACPS) a investigar as bases conceituais e sua aplicação na realidade brasileira. As pesquisas se multiplicaram ao longo dos anos e constituíram acervo considerável, desde 2007. Tais como: Salgado (2007, 2010), Dias (2011), Duarte (2013), Simão (2011), Gimmler Netto (2014), Safe (2015), Gimmler Netto (2016) e Borges (2018). Essas publicações dão origem a um crescente movimento de interlocução entre Paisagem e Morfologia Urbana, que se estabelece e se consolida a partir dos congressos internacionais sobre Morfologia Urbana como o ISUF (2007) e o PNUM (2012), este último congregando estudos brasileiros e portugueses.

0 atendimento a esses seminários e congressos constitui atividade essencial para o aprofundamento de temas e trocas de experiências. Por outro lado, a presença constante e crescente de pesquisadores brasileiros nesses eventos representa um indicativo para que os dirigentes do ISUF investissem e reconhecessem essa participação. Esse fato foi comprovado pela realização do ISUF no Brasil, em 2007, 
com o maior público já presente até então. E, como resultado desse reconhecimento internacional, houve a incorporação de brasileiros nos quadros de representação deliberativa e de conselhos editoriais do Journal of the Seminar on Urban Form, desde 2004, e do PNUM a partir de 2012.

\section{O Laboratório da Paisagem e as pesquisas do grupo}

A realização do ISUF e dos planos diretores, desde 2007, deu visibilidade à produção dos trabalhos dos professores envolvidos que foram convidados para integrar redes de pesquisas em diversas áreas, em destaque, o grupo Quadro da Paisagem (QUAPÁ-SEL), constituído por professores da Universidade de São Paulo (USP), coordenados pelo professor Silvio Soares Macedo. 0 objetivo da pesquisa era investigar o sistema de espaços livres das metrópoles brasileiras e, em específico, a contribuição de Belo Horizonte, Minas Gerais.

As professoras do Departamento de Urbanismo Staël de Alvarenga Pereira Costa, e de Projetos, Marieta Cardoso Maciel e Maria Cristina Villefort Teixeira, envolvidas na rede QUAPÁ-SEL, eram coordenadoras do Núcleo de Pesquisas em Desenho Ambiental inserido no diretório dos Grupos de Pesquisa do Conselho Nacional de Desenvolvimento Científico e Tecnológico(CNPq), criado em 1997.

Com a inserção na rede de pesquisa QUAPÁ-SEL e objetivando estabelecer uma sólida estrutura para a realização dos trabalhos, a criação do Laboratório da Paisagem (LaP) do Departamento de Urbanismo da Escola de Arquitetura da UFMG, vinculada ao PACPS, permite reunir pesquisadores que desenvolvem estudos sobre aspectos referentes aos espaços urbanos e rurais. 0 LaP objetiva construir um arcabouço conceitual e metodológico para o desenvolvimento sustentável das paisagens, aprofundar pesquisas em Morfologia Urbana de cidades brasileiras e aprimorar o corpo de pesquisadores para atuação em planos de desenvolvimento habitacionais e planejamento regional, com repercussões no ensino de graduação e pós-graduação. Ao longo desses anos, o LaP congrega estudantes de graduação e pós-graduação contemplados pela oferta de bolsas de Iniciação Científica (BAT), bolsas de Mestrado e de Doutorado com o fomento do CNPq, Fapemig, FUMP, PRPq/UFMG e outras entidades.

Pelos resultados alcançados com as frequentes publicações do grupo, seus integrantes têm sido acionados para efetuar projetos de extensão nas áreas do paisagismo e habitação, bem como atuar como palestrantes e revisores em periódicos nacionais e internacionais sobre a paisagem e sobre Morfologia Urbana. Também é constante a apresentação de trabalhos em eventos nacionais e internacionais, tais como: Colóquio QUAPÁ-SEL, Encontro Nacional sobre o Ensino de Paisagismo nas Escolas de Arquitetura e Urbanismo do Brasil (Enepea); Colóquio da Paisagem; International Seminar on Urban Form (ISUF); Portuguese Network on Urban Morphology (PNUM) e Habitar.

As pesquisas do LaP, que iniciaram para dar suporte à rede QUAPÁ-SEL, buscavam por levantamentos e caracterizações dos espaços livres de Belo Horizonte. Durante a análise dos dados levantados, percebeu-se a existência de espaços livres intercalados por áreas residenciais que se assemelhavam às características morfológicas denominadas por M. R. G. Conzen (1969), como fringe belts. E, como tais, vislumbrou-se a possibilidade de utilizá-las como conexão entre os elementos definidos por Forman (2014) como matrizes, corredores e manchas e, assim, estruturá-las como um mosaico ecologicamente sustentável, configurando uma inovação na abordagem proposta pelo LaP.

Aliados a esses conceitos, os fringe-belts passaram a ser incorporados às pesquisas sobre as cidades brasileiras, principalmente vinculados às pesquisas do QUAPÁ-SEL. 0 tema, pela sua pertinência e inovação, foi também objeto da dissertação de mestrado de Simão (2011), que concentrou seus estudos nas áreas centrais de Belo Horizonte. Estes estavam sendo desenvolvidos simultaneamente por Meneguetti em Maringá, no Paraná (Meneguetti \& Pereira Costa, 2015), e Cocozza em Uberlândia, Minas Gerais (Cocozza \& Oliveira, 2013).

A investigação dos espaços livres do município de Belo Horizonte, observando os seus limites administrativos, desconsiderou as áreas conurbadas, não permitindo análise sistêmica do todo. Uma nova pesquisa foi então proposta com a inclusão das bordas metropolitanas. Em função de sua extensa escala foi necessária a subdivisão nos quadrantes oeste, norte, sul e leste investigados separadamente. 
Durante a elaboração das pesquisas sobre o sistema de espaços livres, houve a inclusão de um subtema relacionado ao tema global, porém tomado em relação aos espaços livres dos conjuntos habitacionais. Essa pesquisa investigou os projetos dos conjuntos habitacionais implantados no período de 1996 a 2010 e suas respectivas transformações consequentes de ações humanas, desenvolvida com aportes financeiros do CNPq (Teixeira et al., 2014).

No período de 2013 a 2017, outra pesquisa foi simultaneamente desenvolvida pela equipe do LaP sobre a contribuição do urbanista e professor da UFMG Radamés Teixeira para o planejamento urbano do estado de Minas Gerais. Esse estudo visou o levantamento dos diversos planos urbanos elaborados para as cidades mineiras e buscou resgatar a importância do trabalho desenvolvido ao longo da sua profícua carreira acadêmica e profissional (Teixeira et al., 2017).

Com relação aos estudos da Morfologia Urbana, ocorre um fluxo constante nas investigações sobre o tema. Como professores que apresentam os conceitos de Morfologia Urbana em cursos de pós-graduação no Brasil, tornou-se tarefa quase obrigatória desenvolver comparações entre as escolas inglesa e italiana para realizar uma análise morfológica completa, com análises sobre o estudo morfológico no Brasil (Pereira Costa, 2006; Pereira Costa et al., 2007; Pereira Costa \& Teixeira, 2014). Os pesquisadores sentiram a necessidade de refletir sobre as ocorrências que levaram ao estabelecimento das duas escolas, e para isso foi criado um projeto de pesquisa para investigar as evidências de sincronicidade ocorridas no campo da Morfologia Urbana entre os anos de 1940 e 1960, quando pesquisas semelhantes foram desenvolvidas simultaneamente.

A publicação do livro Fundamentos de Morfologia Urbana, em 2015, foi importante pois reuniu conceitos das duas escolas tradicionais na paisagem da cidade colonial de Ouro Preto. A aplicação teórica e prática da Escola Inglesa e o aprofundamento da Escola Italiana de Morfologia Urbana despertaram o olhar de novos pesquisadores para a análise dos tipos edilícios e das transformações da paisagem. Foi significativo o número de trabalhos desenvolvidos sobre o tema após o lançamento do livro, que após a sua segunda tiragem, em 2017, tem sido amplamente adotado por professores e estudantes brasileiros.

Como aporte teórico desta publicação, foram propostas várias pesquisas, entre elas "Encontro de mentes" (Pereira Costa et al., 2013), que buscava apreender os conceitos das duas linhas conceituais das principais escolas morfológicas, e "A sincronicidade nas escolas de Morfologia Urbana e os seus paradigmas sociais", que discutia semelhanças entre os trabalhos desenvolvidos pelos dois fundadores dessas escolas.

Após a publicação do livro Fundamentos de Morfologia Urbana, percebeu-se a necessidade de aprofundar pesquisas que identificavam coincidências entre os estudos efetuados por pesquisadores brasileiros, a saber Sylvio de Vasconcellos e Lúcio Costa, que levaram à proposição da pesquisa "A sincronicidade das escolas de Morfologia Urbana e o seu reflexo em Portugal e no Brasil" (Pereira Costa \& Gimmler Netto, 2015).

Pesquisas em Minas Gerais surgiram da necessidade de contribuir para o resgaste das características tipomorfológicas de um nucleo urbano, Bento Rodrigues, destruído pelo rompimento de uma barragem de rejeitos de minério de ferro, em 2015. 0 levantamento e os estudos visavam a reconstrução de padrões urbanos e tipológicos e condicionaram a oferta de um curso de Morfologia Urbana (Pereira Costa et al., 2017). Os elementos tipológicos vinculados à memória do povoado também foram objeto de uma pesquisa financiada pela Fapemig, no período de 2016 a 2019 (Teixeira et al., 2019b).

Durante a elaboração dos trabalhos, perceberam-se lacunas conceituais referentes às escolas de Morfologia Urbana, demonstrando necessidade de subsidiar aportes metodológicos aos pequisadores. Novas investigações estão sendo realizadas no intuito de aprofundar conceitos inconclusos em abordagens inovadoras que relacionam Morfologia Urbana e paisagem. Essas, denominadas "Territórios e fronteiras nos conceitos não concluídos nas escolas de Morfologia Urbana" e "Abordagens contemporâneas para os conceitos inconclusos nas escolas tradicionais de Morfologia Urbana", encontram-se em desenvolvimento, financiadas pelos órgãos de apoio à pesquisa nacional.

A contribuição do Laboratório da Paisagem com conteúdos teóricos e metodológicos inspira novas investigações e agrega estudiosos sobre o tema em que perpassam transversalmente aspectos geográficos, históricos, culturais, ambientais, econômicos, sociais e urbanos, dentre outras possibilidades que contemplam as paisagens. 


\section{Conclusões}

$\mathrm{O}$ artigo apresentou um panorama sobre a investigação da forma urbana em Minas Gerais, procurando demonstrar que ela é resultado de processos de transformação, nos quais a variável tempo necessita ser integrada às abordagens estritamente formais. Nesse sentido, os estudos sobre Morfologia Urbana devem ser compreendidos como análises processuais, que se fundamentam em aspectos socioculturais da ação humana sobre o ambiente. Isso aproxima os estudos morfológicos dos aportes teóricos da paisagem, evidenciando a ampliação das possibilidades de investigação e entendimentos necessários à compreensão e atuação frente às complexidades da realidade contemporânea.

Esta tem sido a direção seguida pelos pesquisadores do Laboratório da Paisagem (LaP) da UFMG, que aponta para o aperfeiçoamento de conceitos, métodos e experiências que possam ser integrados em abordagens com o objetivo de desenvolvimento socioeconômico, cultural e ambiental, capaz de permanecer ao longo do tempo, favorecendo a sustentabilidade e resiliência das paisagens. Entretanto, buscam-se aportes teóricos e práticos que sejam passíveis de aplicação em diferentes localidades, adaptáveis a diferentes contextos histórico-geográficos, sendo este o maior dos desafios.

Nesse sentido, as bases conceituais e metodológicas incorporadas pelos pesquisadores do LaP precisam ser amplas o suficiente para permitirem diferentes combinações a fim de se adapatarem especificamente a cada estudo de caso, que são ambientes materializados pela ação humana. E não impor o enquadramento e a rigidez metodológica às paisagens analisadas, ignorando particularidades locais. Assim, cada paisagem investigada em sua especificidade é capaz de revelar seu processo de desenvolvimento urbano e territorial.

Ao priorizar esse arcabouço, as fundadoras do LaP contribuem para a formação e capacitação de profissionais que atuam em diversos meios, com destaque para o meio científico-tecnológico com foco em pesquisa e inovação no ensino de nível superior e de pós-graduação. Destaca-se também a atuação de profissionais em gestão urbana e territorial, além da iniciativa privada. Com o intuito de promover a disseminação de conhecimento pela sociedade são continuamente elaborados e realizados cursos de extensão e em formato de curta duração, como oficinas e workshops, para ampliar o acesso social aos conteúdos desenvolvidos e constantemente aprimorados pelos integrantes do LaP.

Juntamente com os esforços para divulgar a Morfologia Urbana por meio de cursos em nível local e nacional, têm sido profícuas as participações em congressos nacionais e internacionais, os quais promovem reflexões sobre a forma urbana que são discutidas nesses eventos. Essa troca frequente entre pesquisadores da Morfologia Urbana tem incentivado investigações e consolidado a disciplina como um campo científico no país, assim como já acontece internacionalmente.

Como exemplificado no decorrer do artigo, os temas das pesquisas realizadas no âmbito do LaP UFMG são sempre atuais e buscam maneiras de se aproximar de soluções fundamentadas nas necessidades reais da sociedade contemporânea. E, em reflexo disso, atraem o envolvimento da comunidade acadêmica, promovendo o alto nível de seus conteúdos por meio de produtos inovadores disponibilizados para a sociedade.

\section{Agradecimentos}

Agradecemos o apoio aos pesquisadores realizado pela FAPEMIG, CNPq e PROAP/CAPES-PACPS-UFMG.

\section{Referências}

Abreu, M. A. (2002). A cidade da geografia no Brasil: percursos, crises, superações. In L. L. Oliveira (Ed.), Cidade: história e desafíos (pp. 42-59). Rio de Janeiro: Ed. Fundação Getulio Vargas.

Barbosa, G. V. (1967). Notas sobre o sítio e posição de Belo Horizonte. Revista da UFMG, 17(1), 9-28. 
Barreto, A. (1996). Belo Horizonte: memória histórica e descritiva: história antiga. Belo Horizonte: Centro de Estudos Históricos e Culturais, Fundação João Pinheiro.

Belo Horizonte. Superintendência de Desenvolvimento da Região Metropolitana de Belo Horizonte. Planejamento da Região Metropolitana de Belo Horizonte - PLAMBEL. (1984a). Favelas na RMBH. Belo Horizonte:

Superintendência de Desenvolvimento da Região Metropolitana de Belo Horizonte.

Belo Horizonte. Superintendência de Desenvolvimento da Região Metropolitana de Belo Horizonte. Planejamento da Região Metropolitana de Belo Horizonte - PLAMBEL. (1984b). Favelas em BH. Belo Horizonte: Superintendência de Desenvolvimento da Região Metropolitana de Belo Horizonte.

Belo Horizonte. Superintendência de Desenvolvimento da Região Metropolitana de Belo Horizonte. Planejamento da Região Metropolitana de Belo Horizonte - PLAMBEL. (1984c). Favelas em BH: estudo de caso. Belo Horizonte: Superintendência de Desenvolvimento da Região Metropolitana de Belo Horizonte.

Borges, E. (2018). Estudo da morfologia urbana de diamantina como subsídio para propostas de normas interventivas em sítio urbano patrimonializado (Tese de doutorado). Belo Horizonte: Escola de Arquitetura, Universidade Federal de Minas Gerais.

Boxer, C. R. (1969). A Idade de Ouro do Brasil. São Paulo: Companhia Editora Nacional.

Bueno, B. P. S. (2011). Com as mãos sujas de cal e de tinta, homens de múltiplas habilidades: os engenheiros militares e a cartografia na América Portuguesa (sécs. XVI-XIX). In Anais do Simpósio Brasileiro de Cartografia Histórica. Belo Horizonte: UFMG.

Cocozza, G., \& Oliveira, L. (2013). Forma urbana e espaços livres na cidade de Uberlândia (MG), Brasil. Paisagem e Ambiente, 32, 9-32. https://doi.org/10.11606/issn.2359-5361.v0i32p9-32.

Conzen, M. R. G. (1969). Alnwick, Northumberland: a study in town plan analysis (The Institute of British Geographers, No. 27). London: Orge Philip \& Son.

Conzen, M. R. G. (2009). As paisagens urbanas históricas na Inglaterra: um problema de geografia aplicada. In L. B. Castriota (Org.). Paisagem cultural e sustentabilidade (Trad. S. A. Pereira Costa). Belo Horizonte: Editora UFMG.

Costa, L. (1995). Lúcio Costa: registro de uma vivência. São Paulo: Empresa das Artes.

Delson, R. M. (1979). Novas vilas para o Brasil-Colônia: planejamento espacial e social no seculo XVIII. Brasilia: Alva, CIORD.

Dias, F. C. (2011). O tratamento dos espaços livres de uma cidade média planejada: o caso de Ipatinga/MG (Dissertação de mestrado). Faculdade de Arquitetura, Universidade Federal de Minas Gerais, Belo Horizonte.

Duarte, J. (2013). Desenvolvimento urbano pós-colonial nas cidades históricas (Dissertação de mestrado). Escola de Arquitetura, Universidade Federal de Minas Gerais, Belo Horizonte.

Forman, R. T. T. (2014). Urban Ecology: Science of Cities. Cambridge: Cambridge University Press.

Freyre, G. (1933). Casa grande e senzala: formação da família brasileira sob o regime de economia patriarcal. Rio de Janeiro: Maia e Schmidt.

Freyre, G. (1936). Sobrados e mocambos. São Paulo: Companhia Editora Nacional.

Fundação João Pinheiro - FJP. (1980). Circuito do ouro Campos das Vertentes: plano de organização espacial e preservação do centro histórico de Tiradentes (Vol. 1). Belo Horizonte: FJP.

Gazzola, A. L. A. (2001). Marianne North: lembranças de uma vida feliz. Belo Horizonte: Fundação João Pinheiro.

Gimmler Netto, M. M. (2014). A paisagem de Ouro Preto (Dissertação de mestrado). Escola de Arquitetura, Universidade Federal de Minas Gerais, Belo Horizonte.

Gimmler Netto, M. M. (2016). Paisagem metropolitana: as formas urbanas dispersas em Belo Horizonte (Tese de doutorado). Escola de Arquitetura, Universidade Federal de Minas Gerais, Belo Horizonte. 
Gomes, L. J. M. (1895). As duas Belo Horizonte: a colonial e a republicana (Direção Aarão Reis). (Planta Geral da Cidade de Minas). Belo Horizonte: Comissão Construtora da Nova capital.

Guerra, M. E. A. (2008). Vilas operadoras de Furnas nas bacias dos rios Grande e Paranaíba da concepção à atualidade (Tese de doutorado). Universidade Federal de Uberlândia, Uberlândia.

Holanda, S. B. (2014). Raízes do Brasil (27a ed.). São Paulo: Companhia das Letras.

Lima, A., Jr. (1962). As primeiras Vilas do Ouro. Belo Horizonte: Santa Maria.

Meneguetti, K. S., \& Pereira Costa, S. A. (2015). The fringe belt concept and the planned new towns: a Brazilian case study. Urban Morphology, 19(1), 25-33.

Pereira Costa, S. A., \& Gimmler Netto, M. M. (2015). Fundamentos de morfologia urbana. Belo Horizonte: C/Arte.

Pereira Costa, S. A. (2006). Estudos sobre a forma urbana. Urban Morphology, 10-2, 142-144.

Pereira Costa, S. A., \& Maciel, M. C. (2008). Urban morphological practice: an example from Brazil. Urban Morphology, 12(2), 139-140.

Pereira Costa, S. A., \& Teixeira, M. C. V. (2014). The study of urban form in Brazil. Urban Morphology, 18(2), 199129.

Pereira Costa, S. A., Bessa, A. M., Teixeira, M. C. V., Maciel, M. C., Meneguetti, K. S., Simão, K. M. C., Salgado, M., Gimmler Netto, M. M., Santos, J. D., Perna, S. A., Safe, S. M. S., Faquineli, L. R., Queiroz, P. A., França, C. C., Alves, R., Lima, T. B., \& Castro, C. M. (2013). Encontro de mentes? Investigações sobre conceitos comuns e abordagens diferenciadas das principais escolas de morfologia urbana (Relatório Técnico). Belo Horizonte: Escola de Arquitetura, Universidade Federal de Minas Gerais, FAPEMIG .

Pereira Costa, S. A., Castriota, L. B., \& Salgado, M. (2011). The World Heritage site of Ouro Preto. Facilities, 29(7-8), 339-351. http://dx.doi.org/10.1108/02632771111130942.

Pereira Costa, S. A., D’Angelo, R., Vianna, C. B. N., Andrade, C., Stubbs, L., Cabrera, L., Rezende, M., \& Xavier, T. (2017). 0 resgate da Morfologia Urbana de Bento Rodrigues. In Anais da $6^{a}$ Conferência da Rede Lusófona de Morfologia Urbana (pp. 109-119). Vitória: UFES. Recuperado em 20 de abril de 2020, de http://pnum2017.wixsite.com/pnum2017

Pereira Costa, S. A., Maciel, M., \& Campos, L. O. (2010). The Public Architecture Programme and the 9 de Março squatter settlement in Barbacena, Brazil. Urban Design International, 15, 105-118. http://dx.doi.org/10.1057/udi.2010.8.

Pereira Costa, S. A., Perna, S. A., \& Simão, K. M. C. (2007). 0 estudo da forma urbana no Brasil. Revista Arquitextos, $1809,87$.

Pinto, M. (1907). Ouro Preto. Revista do Arquivo Público Mineiro, 11, 691-714.

Reis, N. G., Fo. (1968). Contribuição ao estudo da evolução urbana do Brasil: (1500/1720). São Paulo: Pioneira, EDUSP.

Safe, S. (2015). Tradição e vida social na forma urbana da Kasbah dos Oudayas e Medina de Rabat (Dissertação de mestrado). Escola de Arquitetura, Universidade Federal de Minas Gerais, Belo Horizonte.

Salgado, M. (2007). A influência das novas formas urbanas no núcleo histórico da cidade de Tiradentes /MG (Especialização). Escola de Arquitetura, Universidade Federal de Minas Gerais, Belo Horizonte.

Salgado, M. (2010). Ouro Preto: paisagem em transformação (Dissertação de mestrado). Escola de Arquitetura, Universidade Federal de Minas Gerais, Belo Horizonte.

Simão, K. M. C. (2011). Fringe Belts como elementos estruturadores da paisagem: o caso de Belo Horizonte/MG (Dissertação de mestrado). Escola de Arquitetura, Universidade Federal de Minas Gerais, Belo Horizonte.

Suplemento Literário de Minas Gerais. (1970, 26 de setembro). Belo Horizonte: Imprensa Oficial do Estado de Minas Gerais, ano 5, n. 213. Edição especial. Organizada por Francisco Iglésias. Minas Gerais: os viajantes estrangeiros. 
Teixeira, M. C. V., Alonso, P. H., Capute, B., Araujo, G., Costa, S. A. P., Pereira, H. D., Sousa, V., \& Oliveira, A. S. (2010) Plano Local de Habitação de Interesse Social (PLHIS) de Varginha/MG (Relatório Técnico). Varginha: Prefeitura Municipal.

Teixeira, M. C. V., Alonso, P. H., Capute, B., Araujo, G., Pereira Costa, S. A., Pereira, H. D., Sousa, V., Soares, E. F., \& Oliveira, A. S. (2011a) Plano Local de Habitação de Interesse Social (PLHIS) de Barbacena/MG (Relatório Técnico). Barbacena: Prefeitura Municipal.

Teixeira, M. C. V., Alonso, P. H., Pereira Costa, S. A., Capute, B., Araujo, G., Pereira, H. D., \& Oliveira, A. S. (2011b) Plano Local de Habitação de Interesse Social (PLHIS) de Itaúna/MG (Relatório Técnico). Itaúna: Prefeitura Municipal.

Teixeira, M. C. V., Pereira Costa, S. A., Maciel, M. C., Alonso, P. H., Silveira, L. R. G., Resende, L. L., Dias, A. C. V., Fonseca, A. E. P., \& Martins, B. T. (2014). Os espaços livres nos conjuntos habitacionais de Belo Horizonte (Relatório Técnico). Belo Horizonte: Escola de Arquitetura, Universidade Federal de Minas Gerais, CNPq.

Teixeira, M. C. V., Lemos, C. B., Maciel, M. C., Andrade, E., Almeida, R. M., Lima, F. J. M., Faquineli, L. R., Martins, B. T., Barbosa, R. P., \& Moura, P. D. (2017). O urbanista Radamés Teixeira da Silva: contribuições da sua trajetória acadêmica, proposições e projetos (Relatório Técnico). Belo Horizonte: Escola de Arquitetura, Universidade Federal de Minas Gerais, CNPq.

Teixeira, M. C. V., Gimmler Netto, M. M., Maciel, M. C., Salgado, M., \& Pereira Costa, S. A. (2019a). Os modelos das companhias industriais e seus reflexos nas cidades brasileiras. Curitiba: CRV.

Teixeira, M. C. V., Pereira Costa, S. A., Maciel, M. C., Pereira, A. B. M., Medeiros, M. B., Silveira, L. R. G., Gimmler Netto, M. M., Sousa, E. A., \& Ferraz, A. M. T. C., Rezende, V. P. A., Costa, P. G., \& Salgado, M. (2019b). A reconstrução de Bento Rodrigues/MG e a memória do lugar (Relatório Técnico). Belo Horizonte: Escola de Arquitetura, Universidade Federal de Minas Gerais, FAPEMIG.

Vasconcellos, S. (1968). Mineiridade: ensaio de caracterização. Belo Horizonte: Imprensa oficial.

Vasconcellos, S. (1977). Vila Rica: formação e desenvolvimento-residências. São Paulo: Editora Perspectiva.

Editores convidados: Vitor Oliveira (Universidade do Porto, Portugal) e Bruno Zaitter (PUCPR, Brasil)

Recebido: Abr. 20, 2020

Aprovado: Jul. 17, 2020 